Journal of Balkumari College

ISSN : 2467-9321 Website: http://www.nepjol.info/index.php/jbkc

Volume : 9, Issue : 1, June 2020, Page No.: 13-19

\title{
Men from the Lenses of Deepa Mehta in Fire and Water
}

\author{
Dr. Bimala Sharma* \\ Associate Professor
}

\begin{abstract}
Movie in this era has become one of the dominant modes of disseminating perceptions. Women and their issues are vital themes of women centric movies. Stereotypically, these movies display women and their position in patriarchal society. Displaying women and their issues in women centric movies is rationally expected but how men are displayed in such movies has not been given much consideration. Customarily men in such movies are presented negative which have negative impact on their audiences too. This article sets its attention on how men are seen from the lenses of women and shown in women-oriented movies. Deepa Mehta is selected to analyze how she has seen men through her lenses and represented them in Fire and Water. Qualitative research methodology is adopted where Deepa Mehta's Fire (1996) and Water (2005) are the primary data and other resources based on it are secondary. Fire is the story of two lesbian women and Water is about widowhood. Characters like Ashok, Jatin, Mundu, in Fire and Seth, Sadananda and Narayan in Water are studied and found that they are presented as the agents of the patriarchal society. Men are exhibited with all the set masculine traits as strong, brave, bold, intelligent, assertive, aggressive, savior, ruler, educated, handsome, smart, dynamic, powerful who can construct the society as they want. Sexually obsessed men in the movies represent the existing Indian patriarchal society. Abusing woman verbally, physically, mentally and sexually is considered as men's privilege. This justifies that Mehta is unable to deconstruct the notion of masculinity as presented by men directors. She also falls in the trap prescribed by patriarchy and for this she has to present men with all positive and masculine traits and women with negative feminine traits. This kind of representation of men has a large impact on the mass because of unintentional imitation.
\end{abstract}

Key words: masculinity, femininity, patriarchy, Hinduism, Indian society.

\section{INTRODUCTION}

"...movies are considered to be the most popular medium of mass communication (Gargan 11-12). Women and their issues are the fundamental themes of women centric movies. Stereotypically, these movies flaunt women and their state in patriarchal society. Exhibiting women and their issues in women centric movies is reasonably customary but how men are exhibited in such movies has not been given much attention. Mostly men in such movies are presented negative which have negative impact on their audiences too. This article sets its concentration on the issue of how men are seen from the lenses of women and shown in women-oriented movies. Women directed womencentric movies are structured to address women and their issues with the objectives of appealing female audience, hence they exhibit men in different fashion. Major objective of these types of women-oriented movies is either to project strong independent women and their dreams or weak depended women who are suppressed by patriarchy. Thus, these movies primarily on the one hand demonstrate issues of the women protagonists that circumferences domestic life, motherhood, self-sacrifice, romance, etc. on the other they portray men negatively and treat them as "villians" (antagonist). Here Deepa Mehta is chosen to analyze how she sees men through her lenses by exploring her women centric movies Fire and Water. This analysis employs qualitative research methodology. As both of the movies are women centric they criticize patriarchal structures hence compelled to face controversies. Fire is the story of two lesbian women and Water is about widowhood in India. Sexually obsessed men in the movies represent the existing Indian patriarchal society. Abusing woman verbally, physically, mentally and sexually is considered

* Corresponding author: bimalasharma74@gmail.com 
as men's privilege. This kind of representation of men has a large impact on the mass because of unintentional imitation.

\section{LITERATURE REVIEW}

Movie is the mass media to communicate and broadcast opinions to every element of the society. It is an art form which it tries to reflect the society. Movies are of different types having different themes among them women centered movies are one. Generally, the purpose of such movies is to exhibit women and their issues in patriarchal society. Main trait of these movies is they portray men in negative light. Men are superior to women is the basics of world's monotheisms, though some of the major religions additionally embrace countervailing inclinations that value women's divine capacities and demarcate men's supremacy. The ancient Greek philosopher Aristotle portrayed women as naturally men's inferiors in terms of reason.

In the long educational and philosophical tradition that venerated his authority, masculinity was thus rendered both invisible and normative: Feminist theories have been shaped by women's changing place in contemporary societies, and these theories have sometimes proved effective in changing both men's and women's consciousness and conditions (Gardiner 2004). Inequality between the genders is a phenomenon that goes back at least 4,000 years (Lerner 1986). Although the forms and ways in which it has been practiced differ between cultures and change significantly through history, its persistence has led to the formulation of the concept of patriarchy. Key to patriarchy is what might be called the dominant gender ideology toward sexual differences. These differences are used to justify a gendered division of social roles and inequality in access to rewards, positions of power and privilege (Mann and Patterson 2015). Through her studies Jonetta Lauren Lagamba stated that, women have been portrayed with the typical identities of emotionally and physically weak characters, this portrayal led to their subsequent dependence on man. Not only films advertisements billboards and other media also promoting often display women as objectives and stereotyped though women's identities in film are continually, it leads to unstable conclusions about women's personalities. In contemporary cinematic production and research, the viewers often concerned with scholarly investigation of the extensive work that produces a film, this include determining how the character's identities are formed.

This study looked at a total of 72of the top Hollywood films from 2012 for the larger film study. From selected 67 films from 72, 55 of the lead characters were male and only 12 were female. From this the study suggested that, the number of females includes the film in which we considered the gender role to be equal. This is a huge representation of women in the world, and especially in the media. This further proves that men still dominate the cinema and gender is continually misrepresented. In addition to the instances where women are portrayed with positive characteristics, there were films that also allowed men to step outside the limited boundaries of normative male behavior (Smith 2013). It took top 75 highest grossing films in the year 2015 as their sample. Through this study they identified that statistically, there were some minor improvement in the number of lead female character. In the 2015 film compared to the 2012 film study, there are several films with lead female character. In the 2015 film compared to the 2012 film study, there are several films with lead female characters that do not challenge dominant gender narratives and also there were some films with lead female characters that challenge the male dominant narrative (Jeff Smith and Chole Beingy 2015). As "words can be made to mean anything, which is hard to distinguish from the idea that words mean nothing" and this is why imagery becomes more and more powerful (Kilbourne 75).

Similarly gender representation in media influences how people perceive gender issues since some specific gender roles uplift and strengthen the images of men. Goffman concluded that "advertisers do not create the ritualized portrayals they employ, but rather conventionalize what already exists in our society" (as cited in Courtney \& Whipple 24).

Women have been portrayed as sexual objects as Fredrickson and Roberts "The common thread running through all forms of sexual objectification is the experience of being treated as a body (or collection of body parts) valued predominantly for its use to (or consumption by) others" (174).

In similar manner Mazur and Sheehan (2014) note that culture plays a substantial role in regulating the criteria for the ideal female body image. Further Cortese mentions, "the perfect provocateur is not human; rather 
she is a form and hollow shell representing a female figure" (54). If women want to look like the ones in the adverts (perfect woman), they will have to spend a lot of time and money on this never-ending quest. The male gaze constantly reminds women being prospective targets of sexual objectification. Thus, Gauntlett says advertising is oppressive and coercive to women (80).

Movies clearly show the gender power structure where men are depicted as the stronger sex, although some women in movies are portrayed as being strong and independent, they cannot dispute the evident gender power structure. It is interesting to note that there is less gender equality when it comes to gender representation in movies (Alzahrani 2016).

\section{Statement of the problem}

Women have always been the prey of patriarchy which is exhibited in most of Movies directed by men. Female directors too belong to the same patriarchal society hence they also represent men from the same angle.

\section{Research Question}

How men are represented in Deepa Mehta's Fire and Water?

\section{Research Objectives}

The specific objective of this research is to explore Fire and Water to study how Deepa Mehta has seen men through her lenses and represented them.

\section{Rationale of the study}

This study is highly significant because it analyzes how men are represented in women centric movies by women directors as Deepa Mehta. This might open up a new platform to study the real problems on portraying masculinity and femininity and their treatment in movies and society.

\section{Research Methodology}

This study explores Deepa Mehta's Fire and Water to study how men are represented in the women centric movies directed by women. Qualitative research methodology is adopted. Deepa Mehta's Fire and Water are the primary texts and the secondary data consists of collection of texts from libraries, different referential books, journals, internet sources etc. related to the text. Selection, collection, gradation and analysis of primary data consists of repeated watching of the movies then they are described, compared and analyzed to attain the objectives of the research.

\section{DISCUSSION AND FINDINGS \\ Men in Fire}

To explore how men are seen through the lenses of Deepa Mehta and represented in Fire it is necessary to study major masculine characters in the movie. There are three major characters in the movie. Ashok (Kulbhushan Kharbanda), Jatin (Javed Jaffery) and Mundu the servant.

Deepa Mehta in an interview to Hilary Magazine expresses "Fire deals with politics of sexuality." Fire cautiously constructed erotic movie, depicts an allegory of the society which is in tussle of the tug of war in between tradition and modernity. It questions prescribed gender roles. It is the women's suppression of yearning and the spark of sensuality that thrusts the narrative. The film commences in contradiction of the backdrop of Taj, where the recently wedded couple Sita (Nandita Das) and Jatin, who runs a video shop where he sells porn movies are shown trying to come closer to each other. Jatin leaves his wife while on the way back home and straightaway joins his mistress. Gradually Jatin starts losing interest in his wife Sita because of Chinese mistress. This pushes Sita towards her sister-in-law Radha (Shabana Azmi), who is also left to fend for herself however her spouse's evenings are exhausted with the Swami who sermonizes asceticism and counsels that yearning is the origin of all maliciousness. Both the matrimonies are embarrassments. "The Radha Sita relationship shatters the male constructed roles for women. The film, in its own way, questions the social norms which deny the individuality of women and discriminates 
against them on the grounds of morality" (Chatterjee 77). Both of the brothers Jatin who was madly in love with the Chinese girlfriend and Ashoka being a follower of Swamiji did not pay attention to their wives. They didn't even think about their sexual urge which later turned Radha Sita to have lesbian relationship. "In Fire Radha Sita trespass into zones not acknowledged as legitimate, and define a new relationship through individual questionings and go on to deconstruct the patriarchal situation" (Chatterjee 77).

Deepa Mehta while setting directorial gaze on men sees them with all the positive masculine traits and present them in the form of Ashok, Jatin and Mundu. Concentrating on all the three men in Fire Ashok and Jatin it is seen that Ashok, Jatin and Mundu are very strong characters. Though both Ashok and Jatin are unable to satisfy their wives due to some reasons they are shown strong. They don't have to take care of their wives' interests because they are in patriarchal society where men are free to do and behave in any way they like. Even sexual indifference is acceptable for men and there is no respect to women's desires. Despite being newly married man Jatin is not able to sexually satisfy his wife Sita as he is engaged with his Chinese girlfriend. Ashok too is unable to address his wife Radha's sexual desires and seeks refuge to Swamiji on the name of ascetism.

Naming is one of the tools to hammer on the issue hence Mehta chooses name of Hindu Goddesses to women characters as Sita and Radha which symbolizes deities. This clearly signify that she wants to offer extra power to the women characters whereas men are named Jatin and Ashok (name of a king) which are common name without special connotation. This try to indicate that women need extra power like deities to revolt against common men like Ashoka and Jatin. The tussle is to be in between goddesses and men which is not equal.

Sexually both men are unfit for their wives. They are indifferent to the sexual urges of their wives and seek refuge from it one in the lap of girlfriend another in the feet of Swamiji. A man in Indian society controls his wife and the family in spite of all the lacking. He is allowed to make any kind of excuse to preserve his masculinity. Ashoka makes pretense of ascetism there are chances that he is not fit for sexual act because they didn't have baby too. The other masculine character Mundu the servant masturbates while watching Ramayana on television which signify that men are allowed to do anything anytime whereas women are restricted. Men can make fun of such sacred religious things whereas women need to abide by them. Even the servant is shown powerful than the two Radha and Sita.

Sexually obsessed men in the movies represent the existing Indian patriarchal society. Abusing woman verbally, physically, mentally and sexually is considered as men's privilege. Though the physique of both of the brothers doesn't look like as of hero they hold the power as they belong to patriarchal society. On the one hand all the masculine characters are not assertive, confident, brave, bold, rather they look lazy, untidy, dull and on the other both the women Sita and Radha are awesome as they look beautiful, bold, brave, confident, smart, sharp, energetic, neat and tidy. Both the men Jatin and Ashoka are dominant in the family. They need not to be aware of what is going in the house. Radha needs to give the fire examination as in Ramayana Sita does to testify herself as pure. This shows that in today's modern world men are so powerful that they can test women. Finally, both the women recognize their bond and leave the house and unite forever. This justifies that Mehta is unable to deconstruct the notion masculinity as presented by men directors. She also falls in the trap prescribed by patriarchy and for this she has to present men with all positive and strong traits and women with negatives.

\section{Men in Water}

Deepa Mehta in an interview to Hilary Magazine expresses ". . Water with the politics of religion". The film begins with the little girl Chuyia chewing sugar cane in a carefree manner travelling in a bullock cart. Her transformation into a widow, and entry into the widows' home leave her confused, unhappy and unsettled. while she tries to befriend some of the more likeable widows, she resists degradation as well as the finality of her dislocation from home. She tells Narayan that she is here visiting someone. Her desire for freedom is used to dupe her into a final acceptance when, a few months' later, she is shown going in a boat across the river accompanied by Gulabi, the transvestite, who also functions as a pimp. Madhumati although herself a victim of the deprivations imposed on the whole community becomes an oppressor pushing the pretty young widows into prostitution. Chuyia's journey towards freedom turns into one of trauma, leaving her numb and shocked. In the next few scenes a clear move is made from the depressing dark scenes and the seclusion of the river. Now Shakuntala, one of the middle-aged 
widows, take yet another step towards change. She had, in earlier scenes, been instrumental in setting Kalyani free from Madhumati's hold. When Shakuntala discovers the plight of Chuyia, she takes her, carrying her in her arms, towards the railway station where Mahatma Gandhi's train will halt. Shakuntala runs through the streets where hundreds of men and women are also shown going in that direction. At the station Shakuntala pushes through the crowds to reach Gandhi. Narayan who is also moving out of the confines of his home, extends his arms to hold Chuyia as Shakuntala lifts her up.

Deepa Mehta has seen through her lenses and represented men in the similar manner as they are in real patriarchal society in Water. While exploring men in Water there are few major masculine characters as Seth(landlords), Sadananda, and Narayan. They are seen and shown strong men resembling patriarchy through the lenses of Mehta.

Seth are the landlords who are rich. Widow Ashrams are run with the donations given by these landlords. Matriarch of the widow ashram Madhumati send widows to landlords' kothi to satisfy their sexual lust. As the conversation between Rabindra and Narayan clarifies this:

Narayan and Rabindra witness the scene of ferrying Kalyani to the next shore for prostitution and have conversation: "Rabindra: look she went. Narayan: who went? Rabindra: A prostitute to meet some Seth may be my dad. Narayan: Does she looks like a prostitute? Fool she is a widow. Rabindra: I know these landlords have what it is called in English the 'unnatural concern' to these widows. Rarely any of them (landlords) know any of their (widows) names they just know the taller one, shorter one, fat one."

All this justifies widows were sent for the prostitution to run the institution called the ashram which is run on the basis of the donations given by these Seths and in return they get the widows as prostitute. This act is a criticism of how the saviors (Seths) of the ashram and dharma promote prostitution which is against dharma. None can suspect that this kind of act can be conducted in such holy places and by Seths. Not only this when Narayan ask his father's permission to marry Kalyani he directly rejects saying marrying widow is not allowed. Seths are the agents of patriarchy.

Sadananda (Kulbhushan Kharbanda) is employed as a pundit a preacher who injects Hindu holy texts, philosophy, doctrines, disciplinary rules and regulations in the psyche of widows and the people of the society. Sadananda and Shakunatala's debate clarifies: Sadananda: this innocence is our curse. Shakuntala Devi you have been performing this act since how many years how near to the salvation have you reached? Shakuntala: If salvation means detachment then no. Sadananda: Then also don't give up the faith. "The female psyche can be studied as the product of construction of cultural forces" (Showalter 16). This justifies how fake values are injected into the psyche of the widows and how widows are prepared according to the need of the society. Widows "had simply internalized society's norms" (Bloom 14). Kalyani suicides when she knew the Seth who enjoys her body is Narayan's father. Shakuntala after having discussion with Sadananda becomes clear that all the teachings of shastras are meant for continuing the society according to the interests of the powerful ones.

Narayan (John Abraham) is exhibited as the savior. Mehta intentionally names this character Narayan because Narayan is the name of a God in Hinduism. Narayan means Vishnu. Among the three Brahma, Vishnu and Mahesh, Vishnu is the preserver and nurturant so this character is named as Narayan to justify that he can save. He is projected as a strong, handsome, educated, smart, intelligent, bold, brave, dynamic, modern gentleman which are all the positive masculine traits. He has the knowledge of literature like Meghdootam and he plays flute as Krishna so he is presented as a god. At first, he falls in love with Kalyani and tries to help her come out of the ditch of that ashram by marrying her but as Kalyani comes to know that Narayan is the son of the same Seth who satisfy his sexual desire with her, she commits suicide. In the end Narayan is proven to be the savior as Shakuntala hands over the responsibility of Chuyia in the hands of Narayan.

All the three major masculine characters Seth, Sadananda and Narayan are portrayed as the real characters present in the patriarchal society. They are presented as the stakeholders of the society. They are shown as the agents of Patriarchy. All the power is in their (men's) grip and women mere puppets. Men are the perpetrator and the savior. The father (Seth) perpetrates the son (Narayan) saves in case of Chuyia. Seth executes the power of perpetrating violence on widows, Sadananda justifies it with the help of Shastras in Hinduism and Narayan rescues him by leaving him to continue exercising his power. 


\section{CONCLUSION}

Movies are the dominant mode of mass communication in today's world. Women and their issues are the essential themes of women-oriented movies. Stereotypically, these movies parade women and their state in patriarchal society. Thus, these movies primarily on the one hand demonstrate issues of the women protagonists that circumferences domestic life, motherhood, self-sacrifice, romance, etc. on the other they portray men negatively and treat them as "villians" (antagonist). Deepa Mehta's both of the movies Fire and Water are women centric they criticize patriarchal structures hence compelled to face controversies. Fire is the story of two lesbian women and Water is about widowhood in India. Sexually obsessed men in the movies represent the existing Indian patriarchal society. Abusing woman verbally, physically, mentally and sexually is considered as men's privilege. The men analyzed here from the movies are Ashok, Jatin and Mundu from Fire and Seth, Sadananda and Narayan from Water.

The men analyzed here are Ashok, Jatin and Mundu. Though the physique of both of the brothers doesn't look like as of hero they hold the power as they belong to patriarchal society. They are not assertive, confident, brave, bold, rather they look lazy, untidy, dull whereas both the women Sita and Radha are awesome as they look beautiful, bold, brave, confident, smart, sharp, energetic, neat and tidy. Both the men Jatin and Ashok are dominant in the family. They need not to be aware of what is going in the house. Radha has to appear in the fire examination as in Ramayana Sita does. This shows that in today's modern world men are so powerful that they can test women. Even Mundu the servant is presented stronger who can mock at Ramayana the Shastra and masturbate in front of the eldest member of the family Biji because she is female.

Narayan is shown as the savior because he plays flute like the god Narayan and he finally saves Chuyia. He is projected as a strong, handsome, educated, smart, intelligent, bold, brave, dynamic, modern gentleman which are all the masculine traits. All the three major masculine characters Seth, Sadananda and Narayan represent as the real characters from the patriarchal society. They are presented as the stakeholders of the society. All the power is in their (men's) grip and women is mere puppets. Men are the perpetrator and the savior. The father (Seth) perpetrates the son (Narayan) saves in case of Chuyia. Seth executes the power of perpetrating violence on widows, Sadananda justifies it with the help of Shastras in Hinduism and Narayan rescues him by leaving him to continue exercising his power. This justifies that Mehta is unable to deconstruct the notion of masculinity as presented by men directors. She also falls in the trap prescribed by patriarchy and for this she has to present men with all positive and strong masculine traits and women with feminine negative traits. This kind of representation of men has a large impact on the mass because of unintentional imitation.

\section{WORKS CITED}

Alzahrani, Fahad. "The portrayal of Women and Gender Roles in Films," International Journal of Scientific \& Engineering Research, Vol.7, Issue 4, April 2016, 533-534.

Arabi, Peegah. Interview, Hilary Magazine, Saturday, June 2, 2007.

Bloom, Harold. (ed.), Alienation. New York: Infobase, 2009.

Chatterjee, Madhuri. “Women's Bodies, Women's Voices: Exploring Women's Sensuality in Deepa Mehta's Trilogy”, Films, Literature \& Culture Deepa Mehta's Elements Triology,Ed. Jasbir Jain, New Delhi: Rawat Publications, 2007, 75-84.

Cortese, A. J. (2004). Provocateur: Images of Women and Minorities in Advertising. Lanham: Rowman \& Littlefield.

Courtney, A. E and T.W. Whipple. (Spring 1974). "Women in T.V. Commercials." Journal of Communication 24. 2: 110-118. Print.

Fire. Dir. Deepa Mehta, Prod. David Hamilton. Perf. Shabana Azmi, Nandita Das, Kulbhushan Kharbanda, JavedJaffery, 1996.

Fredrickson, Barbara \& Tomi-Ann Roberts. (1997). “Objection Theory. Towards Understanding Women's Lived Experiences and Mental Health Risks." Psychology of Women Quarterly 21. 2:173-206.

Gardiner, J. K. (Ed.), "Men, Masculinity and Feminist Theory." Handbook of Studies on Men \& Masculinities. March 2004. https://www.corwin.com/sites/default/files/upm.../5177_Kimmel_Chapter_3.pdf

Gargan, Edward A. 'In ‘Bollywood,'Women Are Wronged Or Revered.” The New York Times. Jan 17, 1993: 11-12. 
Gauntlett, David. (2002). Media, Gender and Identity: An Introduction. London: Routledge.

Kilbourne, Jean. (2000). Can't Buy My Love: How Advertising Changes the Way We Think and Feel. New York: Simon \& Shuster.

Lagmba, Jonette Lauren. "Shaping Identity: Male and Female Interactions in Cinema." Graduate Theses and Dissertation. University of Florida, 2012.

Lerner, Gerda. The Creation of Patriarchy. New York: Oxford University Press, 1986.

Mann, Susan Archer and Patterson, Ashly Suzanne. Reading Feminist Theory from Modernity to Postmodernity. Oxford University Press, Incorporated, 2015.

Mazur, A. (1986). "U. S. Trends in Feminine Beauty and Over adaptation." Journal of Sex and Research 22: 281303. Print.

Sheehan, K. (2014). Controversies in Contemporary Advertising. Thousand Oaks, CA: Sage Publications.

Showalter, Elaine. "Feminist Criticism in the wilderness", Writing and Sexual Difference. Ed. Elizabeth Abel, Sussex: The Harvester Press, 1982.

Smith, Jeff and Chloe Beighley. Normalizing Male Dominance: A Study in Gender Representation in 2015 Films. https:/griid.files.wordpress.com/2009/04/gender-representation-in-2015-films.pdf

Smith, Jeff. "Normalizing Male Dominance: Gender Representation in 2012 Films." Film study, gender representation in Hollywood Films, GRIID, 2013.

Water. Dir. Deepa Mehta, Prod. David Hamilton, Perf. Lisa Ray, John Abraham, Sarala, Seema Biswas, 2005. 